\title{
RESIDUAL HEAT POWER REMOVAL FROM SPENT NUCLEAR FUEL DURING DRY AND WET STORAGE
}

\author{
DANIEL VLČEK
}

\begin{abstract}
Department of Nuclear Reactors, Faculty of Nuclear Sciences and Physical Engineering, Czech Technical University in Prague, V Holešovičkách 2, Praha 8, Czech Republic

correspondence: daniel.vlcek1@gmail.com
\end{abstract}

\begin{abstract}
This project deals with the thermal analyses of the wet and dry storages of the spent nuclear fuel. The dry spent fuel storage sub-channel code COBRA-SFS has been used in order to calculate the temperature field. In this code, the new model of residual heat removal was created for the SKODA 1000/19 cask where the spent nuclear fuel TVSA-T type from NPP Temelin will be stored. The object of calculations was to obtain the inside temperatures under maximum loads. After that, the results were compared to the requirements of the local regulatory body. Because of the absence of experimental data, the validation of the created computational models could not be accomplished. However, according to the verification scheme of the COBRA-SFS authors, the verification of the new models was implemented.
\end{abstract}

KEYwORDs: Spent nuclear fuel, residual heat removal, dry storages, TVSA-T fuel, thermal analysis, subchannel analysis.

\section{INTRODUCTION}

A steel cask is a multifunctional system for storing and for transporting spent fuel. As other options, it has to guarantee the cooling of fuel assemblies. This requirement is of primary importance to fuel integrity preservation and, from the regulatory point of view, it is fulfilled if cladding temperature is below the prescribed limit of $350{ }^{\circ} \mathrm{C}$ in the Czech Republic which is in agreement with IAEA safety guides [1].

In this frame, the thermo-fluid dynamics of spent fuel storage casks are a key aspect of safety analyses. In the 80s, thermal analyses were carried out for low burnup fuel (around $30 \mathrm{MWd} / \mathrm{kgU}$ ) stored in casks as CASTOR (Wheeler et al. [2]; Rector et al. [3]), TN24P (McKinnon et al. 44), and REA-2023 (McKinnon et al. [5]). The thermal analyses were performed with vacuum, nitrogen, and helium backfill environments in both vertical and horizontal cask orientations.

At the time, thermal calculations were conducted with the subchannel code COBRA-SFS, which is an extension of COBRA (thermal-hydraulic analysis computer code). COBRA-SFS retains all the important features of the COBRA codes for single-phase analysis, and extends the range of application to problems with two-dimensional radiative and three-dimensional conductive heat transfer to allow analyses of multiassembly spent-fuel storage and transportation systems (currently the newest version - cycle 4 came out [6]). The code allows for steady-state threedimensional modeling and uses a control-volume approach to solve the mass, momentum and energy conservation equations to determine pressure, temperature and velocity fields, under forced and natural convection heat transfer conditions, in both steadystate and transients. The steady-state form of the

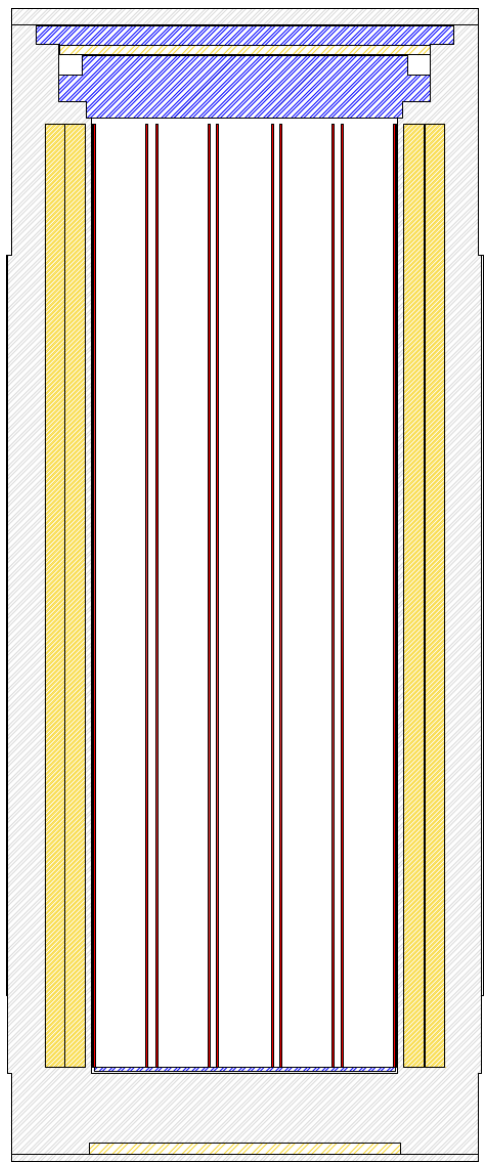

Figure 1. Horizontal cut of the model SKODA 1000/19 storage cask.

differential equations is solved in each of the three orthogonal coordinate directions as if they were three independent one-dimensional problems. 
Nowadays, high burnup of spent fuels $(<60 \mathrm{GWd} / \mathrm{tU})$ as well as proliferation of dry cask storage due to in-pool storage limitations, have made it necessary to update thermal analyses addressing current conditions and cask designs. In addition, as most countries have not made a decision concerning the last stage of the nuclear fuel cycle yet, an extension of thermal studies to time spans up to 300 years seems recommendable [7].

In present cask analyses, thermal calculations are often carried out with Computational Fluid Dynamics (CFD) 3D codes, so that an accurate insight into the thermal response of the cask is achieved. The hypothesis and approximations taken into account are an important part of the methodology applied. A proper procedure is fundamental to obtain a sound thermalfluid dynamic characterization of the simulated system. However, a commitment between a sound characterization and the computational cost should be considered 8.

Models in COBRA-SFS have never been validated for eastern type fuel with triangular geometry. Although the authors of the code guarantee errorless function, the correct application brings problems that are not discussed in the available literature.

\section{MODELING THE STORAGE CASK}

The main object of this work was to obtain thermal distribution of the SKODA 1000/19 storage cask built in Czech Republic in the SJS company. It has been developed from the CASTOR 1000/19 produced by the German GNS [9]. The dimension parameters are classified and therefore could not be specified here. Firstly, a simplified model has been created for the vertical position used for storing. Horizontal cut of this model, see Fig. 1, can be divided in three parts - top, middle and bottom structures. In the centre part the channel region is located and will be discussed in detail. In order to calculate reverse flow in the sub-channel model, COBRA-SFS (Cycle 4) 6 enables to use the plenum model which represents top and bottom structures. The channel inlet and outlet conditions are then calculated in the code as required to satisfy overall mass conservation in the system and any specified assembly pressure drop boundary conditions. The plenum model assumes a one-dimensional node for the fluid, but the conduction heat transfer paths in the plenum regions can be radially and axially non-uniform. It is also possible to include heat losses through the sides of the plenum region, as well as through the top or bottom.

Natural circulation is created in the cask with helium backfill at approximately $40 \mathrm{kPa}$. Therefore the helium data could be derived from lit. [10. The solid structure of cask is made out of steel (blue in the Fig. 1) and the main part of cast iron (grey). For the purpose of moderating neutrons the polyethylene plates and rods have been used (yellow). The material properties data were obtained from Matweb [11.

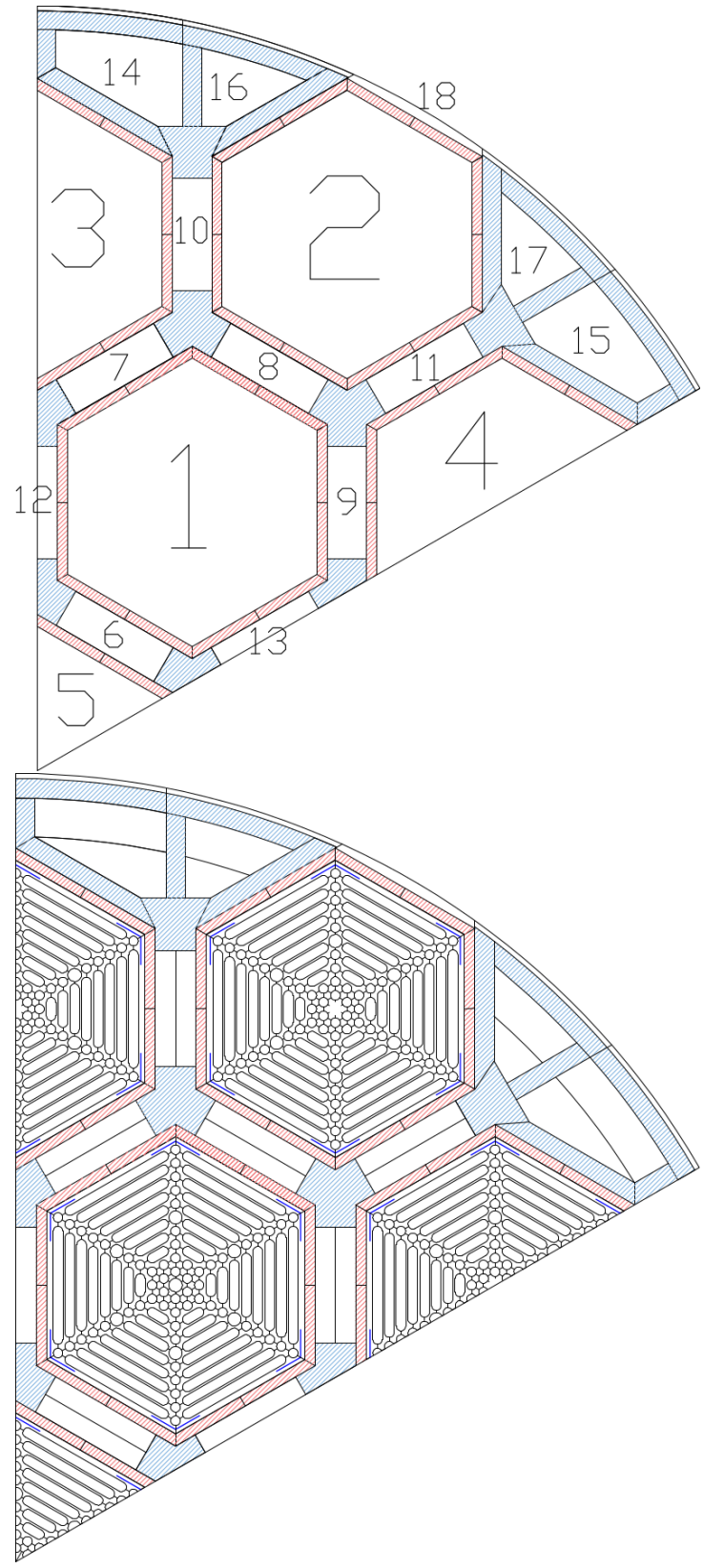

Figure 2. Lateral section of the model SKODA 1000/19 storage cask with highlighted assemblies (top) and all subchannels (bottom).

Fuel assemblies are held in the channel region by a carry grid built from a combination of borated and clean aluminium alloys to maintain the system below criticality. There are 19 positions for fuel assemblies in the cask and thanks to the symmetry the model could have been simplified to one sixth, cf. Fig. 2. In the COBRA-SFS code it is necessary to split the model into channels, slab parts, rods and surroundings in the form of plena.

It can be also seen 18 isolated areas - assemblies which are not connected to each other in lateral direction in the top Fig. 2. The whole model is divided into 48 axial nodes each consists of 256 sub-channels, see bottom Fig. 2 and 90 slab structures. 


\subsection{BOUNDARY CONDITIONS}

The boundary conditions are key input parameters used for calculation of temperature field. For this analysis the residual heat power of fuel assemblies and surrounding temperature have been used. The temperature was set to $38^{\circ} \mathrm{C}$. The value of heat power which is generated by fuel assembly was derived from the potential maximum load of storage cask - 21.68 $\mathrm{kW}$. The input data of residual heat was then divided into three schema. Homogeneous option (Scheme A) with $1141 \mathrm{~W}$ per fuel assembly and two heterogeneous with maximum - $1334 \mathrm{~W}$ in the centre (Scheme B) and the last (Scheme C) has power peak - $1264 \mathrm{~W}$ in the second row. The company SJS uses these schemes as well, however at the end the author did not obtained the data from their calculations. Despite this the three schemes remained the same, but the analysis could not be validated or at least calibrated.

\subsection{TVSA-T FUEL}

After the residual heat power was set, the axial and radial heat profile had to be maintained for the TVSA$\mathrm{T}$ fuel. The radial profile was set to be simply homogeneous, however the axial profile was calculated using a module of SCALE 6.2.2 called TRITON that combines the transport code NEWT for nuclear data preparation for the computational procedure with the depletion code ORIGEN. The results of axial profile can be seen for different enrichment and burn-up in Fig. 3 The value of $4.4 \%$ and $50 \mathrm{MWd} / \mathrm{kgU}$ were chosen and the time dependence on residual heat power was estimated as is presented in the Fig. 3

The homogeneous radial profile serves as first approximation. It is not ideal, however it was easier to spot possible errors in the input file. For the future work would be necessary to add radial profile. It would affect the temperature peaks described below. The parameters of TVSA-T fuel are summarized in the table 3 below.

The fuel assemblies have been simplified by lumping together the fuel rods as well as the subchannel around them. The simplification was made due to computation time especially in the peripheral parts. The number of fuel rods has been reduced to 115 from 331 and the number of sub-channels from 720 to 78 . Because of the symmetry, the assemblies were not the same. In the input file of COBRA was necessary to create them separately as well as in the input file of RADGEN as can be seen in the Fig. 2

\subsection{HEAT TRANSFER AND OUTLET CONDITIONS}

Heat transfer is realized from the fuel assemblies by the form of conduction, convection and radiation. The contact of fluid with fuel rods is described by the Nusselt number which is equal to 3.66 for the laminar flow and for the turbulent flow the DittusBoelter equation can be used. However the turbulent

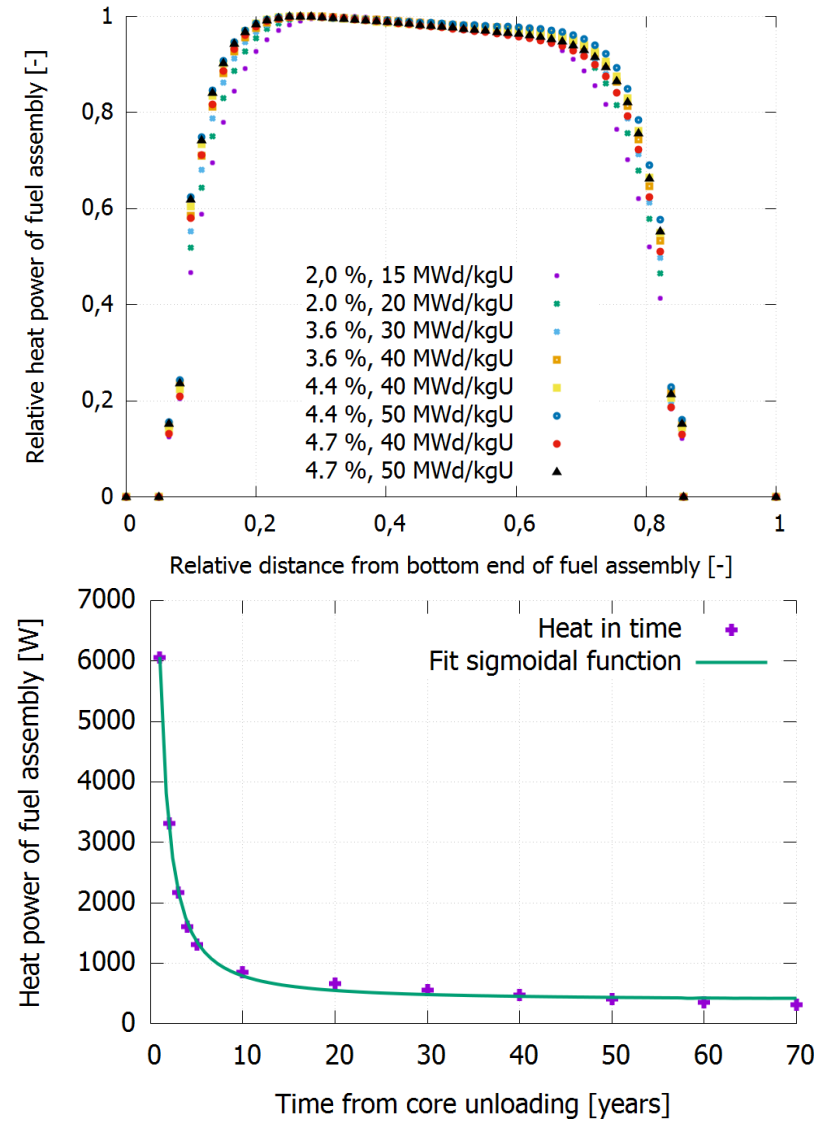

Figure 3. Axial profile (top) and dependence of heat power on time (bottom) of TVSA-T fuel.

flow practically did not occur due to low velocities of helium inside the cask.

The pressure loss was derived with the use of grid factor equal to $100 / R e$ [12. Axial heat transfer in the fluid was neglected and the thermal resistance between adjacent nodes was used in order to obtain axial and radial conductive heat transfer.

For the radiation heat transfer it was necessary to estimate radiation view factors of black/grey bodies. The RADGEN code, a standalone module of COBRASFS, was used for the fuel assemblies. View factors of the empty ones were defined using Hottel's method together with the Cox string correlation [13. After the calculation of view factors was done, the emissivities of surfaces had to be set. Literature advises to use a value of emissivity equal to 0.8 for oxidized zirconium surface, 0.6 for aluminium surfaces and 0.4 for the steel ones [14.

Closure of the set of equations was realized by adding the outlet conditions. The first was the outlet temperature, in this case uniform in axial direction. The second very important part was to set the outlet conditions of the cask and the two plena. The correct way for obtaining thermal resistivity of these parts is measuring it, however authors of COBRA-SFS [5] recommend a theoretical approach where the heat flux at the sides is calculated as follows. The most universal equation for the heat transfer is (regarding 

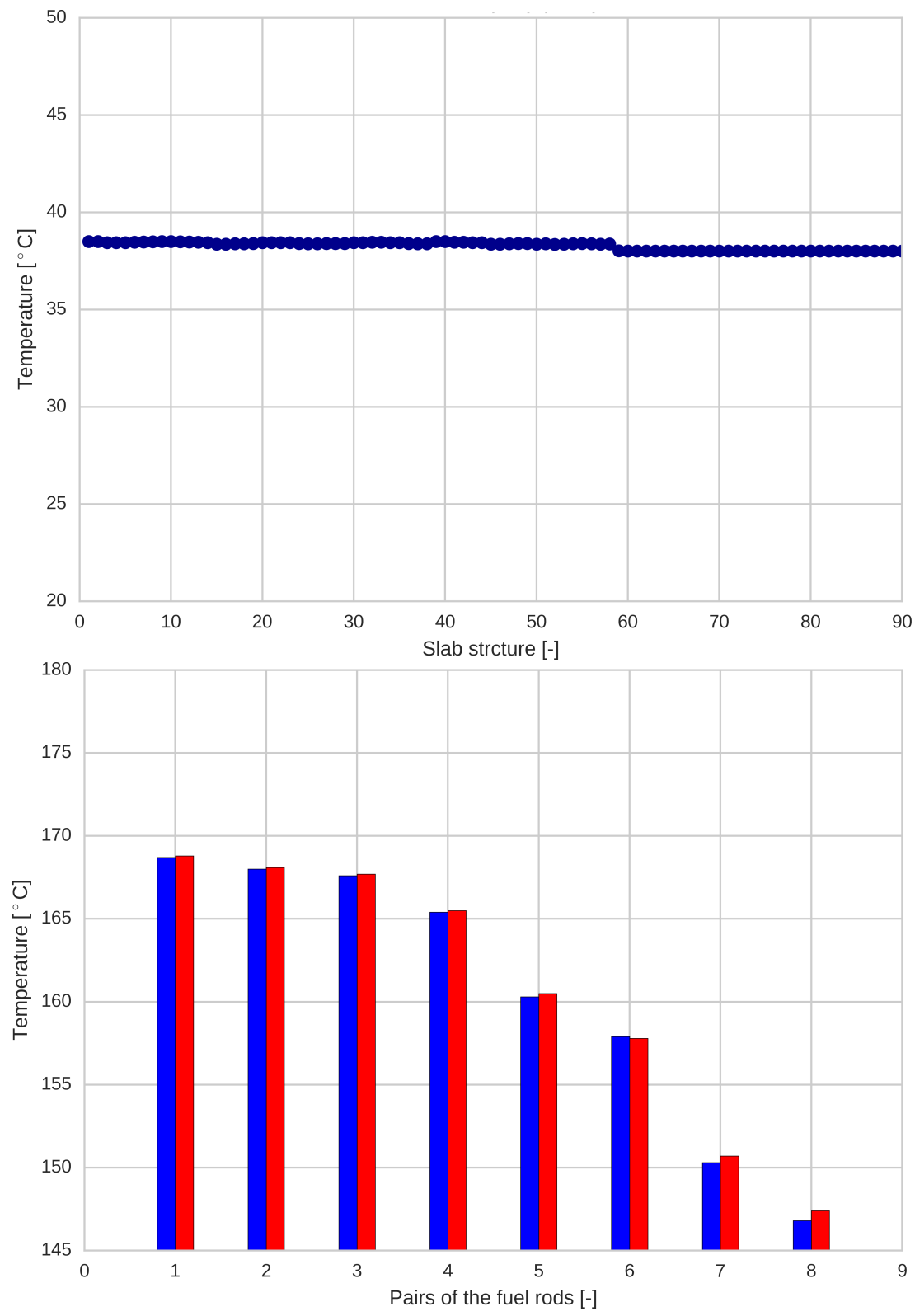

FiguRE 4. Verification step 3 (top) with the temp. of all slab structures and step 4 (bottom) with pairs of selected fuel rods in assembly 3 vs. 4 .

radiation heat transfer):

$$
q=C_{1} \cdot\left[C_{2}\left(T_{i}-T_{i+1}\right)\right]^{C_{3}} \cdot\left(T_{i}-T_{i+1}\right),
$$

Nevertheless this relation is often overly complex. The maximal simplification is achieved in the case of the connection of two solid structures - conduction connection. The coefficients are set as:

$$
C_{1}=\frac{\lambda}{l}
$$

where $\lambda$ is thermal conductivity and $l$ is the width of connection. $C_{2}=1, C_{3}=0$. For the peripheral parts of cask which are in contact with fluid it is necessary to use a different approach to include natural convection. Usually the approach with a Nusselt number is chosen:

$$
N u=\frac{\alpha \cdot l}{\lambda}=c_{1} \cdot(\operatorname{Gr} P r)^{c_{2}},
$$

where the constants $c_{1,2}$ depend on the choice of a natural convection correlation and the solution leads to these equations:

$$
C_{1}=c_{1} \cdot\left(\frac{\lambda}{l}\right) ; \quad C_{2}=\frac{g \cdot \gamma \cdot l^{3} \cdot \rho^{2} \cdot c_{p}}{\eta \cdot \lambda} ; \quad C_{3}=c_{2}
$$

This approach of setting the outlet conditions can be used as the first estimation of heat flux through the cask. Other option can be setting the coefficients as stated above and then change them preserving the ratios between them in order to achieve desired temperature. The last option can be setting a different value of Nusselt number for laminar flow, which was set to 3.66 (Experimental data from [5]) and bias the rod wall temperatures. 

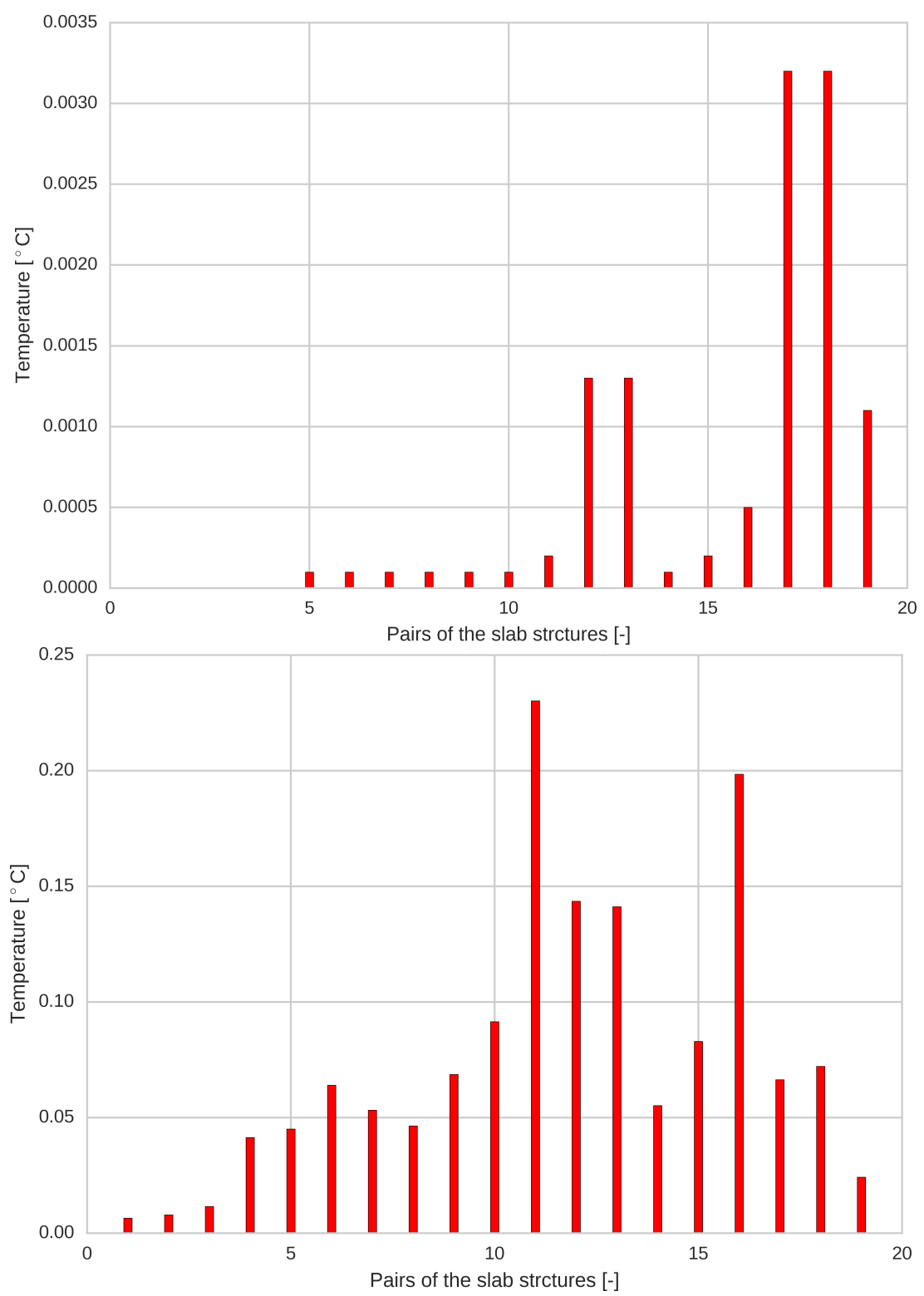

Figure 5. Verification step 3 (top) and 4 (bottom) with the temperature differences of absorption rods.

\section{VERIFICATION}

Having successfully developed an input file for the COBRA-SFS code, the next task is verifying that the model correctly represents the system being modelled. The input error checking in the code will readily capture actual mistakes in the input stream, but it will not generally capture errors in the consistency of the input. Long experience [6] with this process has shown that the following steps can reliably uncover most, if not all, such errors in consistency of input.

(1.) Running the model with zero decay heat generation, uniform temperature specified on all boundaries, omitting thermal radiation modeling

(2.) Running the model with zero decay heat generation, uniform temperature specified on all boundaries, add in thermal radiation modeling in the fuel assemblies
(3.) Same conditions as Step 2, but expand group RADG to include user-defined black body view factors in open assemblies, in group RADG

(4.) Run the model with all thermal radiation modeling included and uniform decay heat generation rate in all assemblies with fuel rods

After each step the symmetry and consistency of boundary temperature must be compared. For better illustration, the temperature differences were plotted into bar charts. During the first three steps there was no heat generation. After elimination of the occurred errors the figures from these steps were exactly the same. The difference appeared at the last step. In the Fig. 4 on the left the temperatures of the slab structures are plotted. It seems that some errors could not have been erased however the temperature difference is about $0.4{ }^{\circ} \mathrm{C}$. The same fact can be observed in the Fig. 5 , resp. 6 , where the temperatures of absorption 

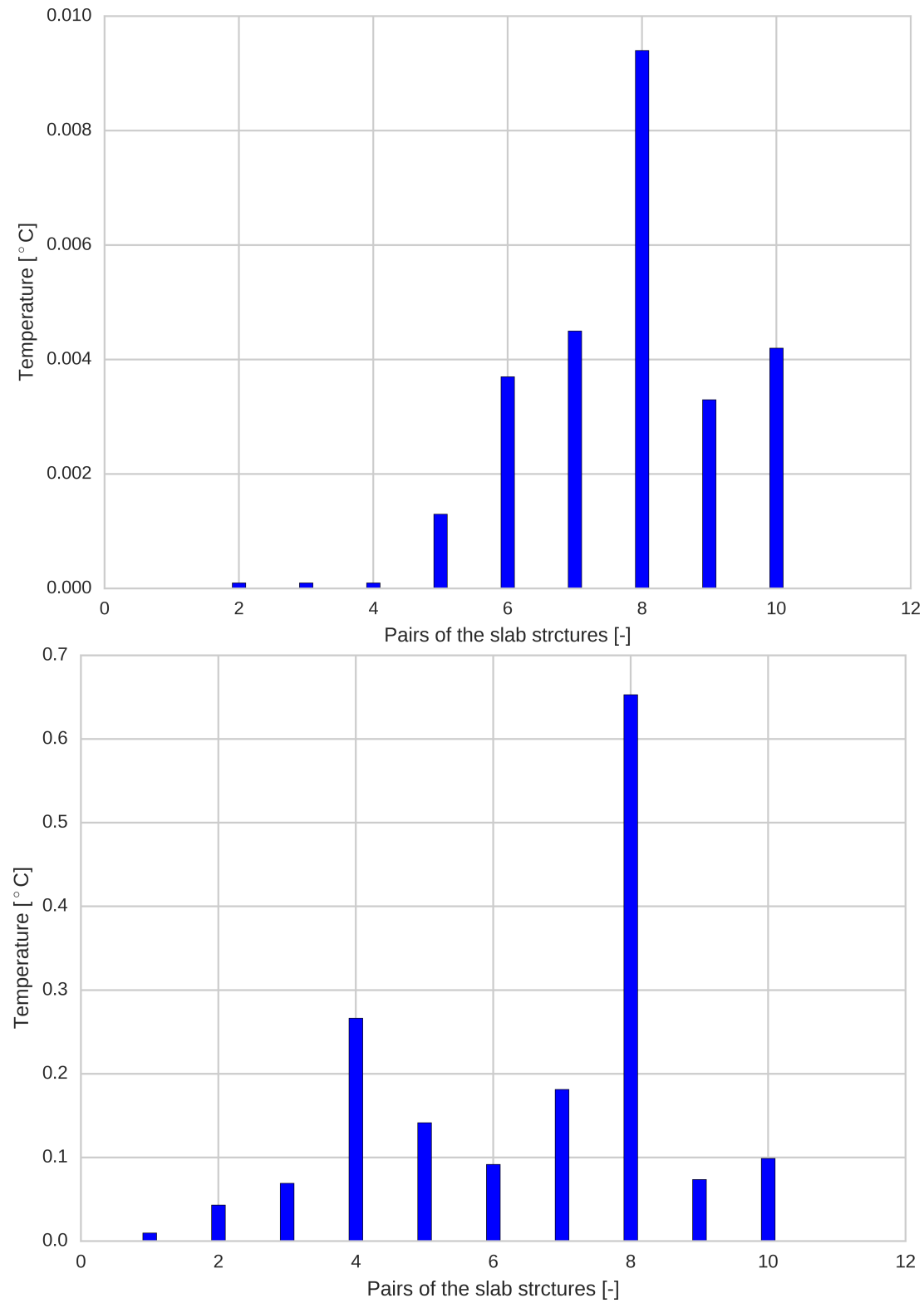

Figure 6 . Verification step 3 (top) and 4 (bottom) with the temperature differences of peripheral basket structures.

rods (aluminium structures around fuel assemblies), resp. peripheral parts of the basket are plotted. When the heat generation was included the differences went higher, however maximal value of the difference was 0.65. In the Fig. 4 on the right the symmetry of fuel rods between assembly 3 and 4 is presented. The maximal temperature difference was also lower than 1 ${ }^{\circ} \mathrm{C}$ therefore the model has been declared verified.

The validation of this model could not be done, because the data from SJS were not from commercial purposes available also the accessible literature does not provide any data from measurements of SKODA or CASTOR 1000/19. The SJS used CFD approach with the ANSYS code.

\section{Results}

\subsection{Maximum temperature}

The main object of the computation is to calculate the temperature in the most heated rod in the whole cask. From the regulatory point of view, the cask can be authorized if cladding temperature is below the prescribed limit of $350{ }^{\circ} \mathrm{C}$ [1. In the Fig. 7 it can be seen that the limit is fulfilled for all loading schema with maximal heat power of $21.68 \mathrm{~kW}$. The relative distance is measured for the whole fuel assembly and in the figure the position of fuel in the assembly together with axial profile can be clearly observed. The maximum temperature is located in the centre of middle fuel assembly in the case of loading schemes A and B. In the case of the loading scheme $\mathrm{C}$ the maximum lies in the first row (see assembly 1 in Fig. 2). Temperatures are specified in the Tab. 1 


\begin{tabular}{cc}
\hline Loading & Temperature $\left[{ }^{\circ} \mathbf{C}\right]$ \\
\hline Scheme A & 306.7 \\
Scheme B & 316.5 \\
Scheme C & 311.1 \\
\hline
\end{tabular}

TABLE 1. Summary of maximal cladding temperatures during different loads.

The maximum lies $2149 \mathrm{~mm}$ from the bottom of the cask (4550 $\mathrm{mm}$ in total length).

\subsection{RAdial Distribution OF TEMPERATURES}

Radial distribution of the slab structure temperatures is shown in the Fig. 8. There three rows of fuel assemblies can be seen together with solid nodes in the cask. On surface the temperature should not exceed the limit of $85^{\circ} \mathrm{C}$ as far as the NPP ETE requires. This requirement was almost fulfilled with temperature 88 ${ }^{\circ} \mathrm{C}$. However the results cover the highest possible load and the calculations slightly overpredict the actual data. The radial profile should be flattened however in the figure only the solid structures are plotted. If the temperatures of surrounding sub-channels were also plotted, the profile would be more balanced especially between fuel assemblies.

The decrease of temperature at the peripheral cask structure is a result of conductive heat transfer with low thermal resistance. In the figure the maximum under the scheme $\mathrm{C}$ can also be discerned to be located in the first row instead of the centre of cask.

\subsection{TIME DEPENDENCE ON MAXIMAL TEMPERATURE}

The last studied parameter in detail is the axial dependence of cladding temperature on time. The effect of axial distribution is mentioned above. The development of heat power in time is presented in the bottom part of Fig. 3. The data from here were the input parameters and led to an axial temperature evolution, see Fig. 9] As a result of radioactive decay the heat power decreases together with the maximal temperature, however even after 50 years the temperatures inside the cask reach $150{ }^{\circ} \mathrm{C}$.

\subsection{FLOW RATE}

The flow rate inside the cask has been changing from the initial guess by iterative solution to its actual value on the basis of natural circulation. Maximum of the flow was obviously heading upwards in the centre of the cask (considering the whole assemblies), where the highest temperatures occurred (except the loading scheme $\mathrm{C}$ ), and it was constantly decreasing in the assemblies 1, 3, 4, 2 .

Even in some peripheral sub-channels of these assemblies the flow direction has changed. The flow rate was completely downwards in the peripheral assembly no. 18. Mean values of flow rates are presented

\begin{tabular}{cccc}
\hline Scheme & A & B & C \\
\hline Assembly 1 & $5.53 \mathrm{E}-6$ & $6.35 \mathrm{E}-6$ & $7.94 \mathrm{E}-6$ \\
Assembly 2 & $4.54 \mathrm{E}-7$ & $-6.35 \mathrm{E}-7$ & $-5.44 \mathrm{E}-7$ \\
Assembly 3 & $1.04 \mathrm{E}-6$ & $9.98 \mathrm{E}-7$ & $6.80 \mathrm{E}-7$ \\
Assembly 4 & $1.09 \mathrm{E}-6$ & $9.98 \mathrm{E}-7$ & $6.80 \mathrm{E}-7$ \\
Assembly 5 & $1.36 \mathrm{E}-6$ & $1.77 \mathrm{E}-6$ & $7.71 \mathrm{E}-7$ \\
Assembly 18 & $-9.53 \mathrm{E}-6$ & $-9.53 \mathrm{E}-6$ & $-9.53 \mathrm{E}-6$ \\
\hline
\end{tabular}

TABLE 2. A summary of flow rates $[\mathrm{kg} / \mathrm{s}]$ in different assemblies and loads

in Table 2. The total flow direction has switched in assembly 2 in schemes B and C. It was probably due to the fact that the peripheral assembly 18 could not transfer more fluid and therefore a part of the flow has moved to different assemblies.

\section{Conclusions}

Simplified model of the multifunctional storage cask SKODA 1000/19 containing TVSA-T fuel assemblies has been created. The input file for the code COBRASFS has been prepared together with input data from code RADGEN providing radiation view factors that are necessary for the radiation heat transfer. In the model the inner carrying parts were modelled in detail, however at the peripheral parts, especially at top and bottom of the cask many approximations were used. To complete the model material properties, boundary conditions were added. The initial parameters of the spent fuel were obtained from the ORIGEN code. The boundary conditions were estimated with the use of the methodology of the COBRA code creators.

The important part connected with creating a new model is its verification. Here the four-steps-long verification process is carried out. The solution consists of three steps with no heat power generation and the last step with it already included. This procedure should cover most of the potential errors made during creating the input file. In the output data the undesirable temperature peaks are searched for together with asymmetries in the results. In the first three steps, the temperature should be equal to the surrounding temperature. Seeing that the temperature differences in observed symmetry have not surpassed $1{ }^{\circ} \mathrm{C}$ even in the last step, the model has been declared verified. The validation or at least calibration could not be done since the data are from the commercial purposes classified.

The main object of this work was to find out whether the COBRA-SFS code can predict temperature field in a storage system with triangular geometry even though it has not been validated for that. It is shown that it is possible, however the COBRA manual has not clarified many of the potential questions and it depends strongly on the researcher, how the problems will be solved.

The results are discussed in the last part of this paper. It shows that the safety guide recommendation 


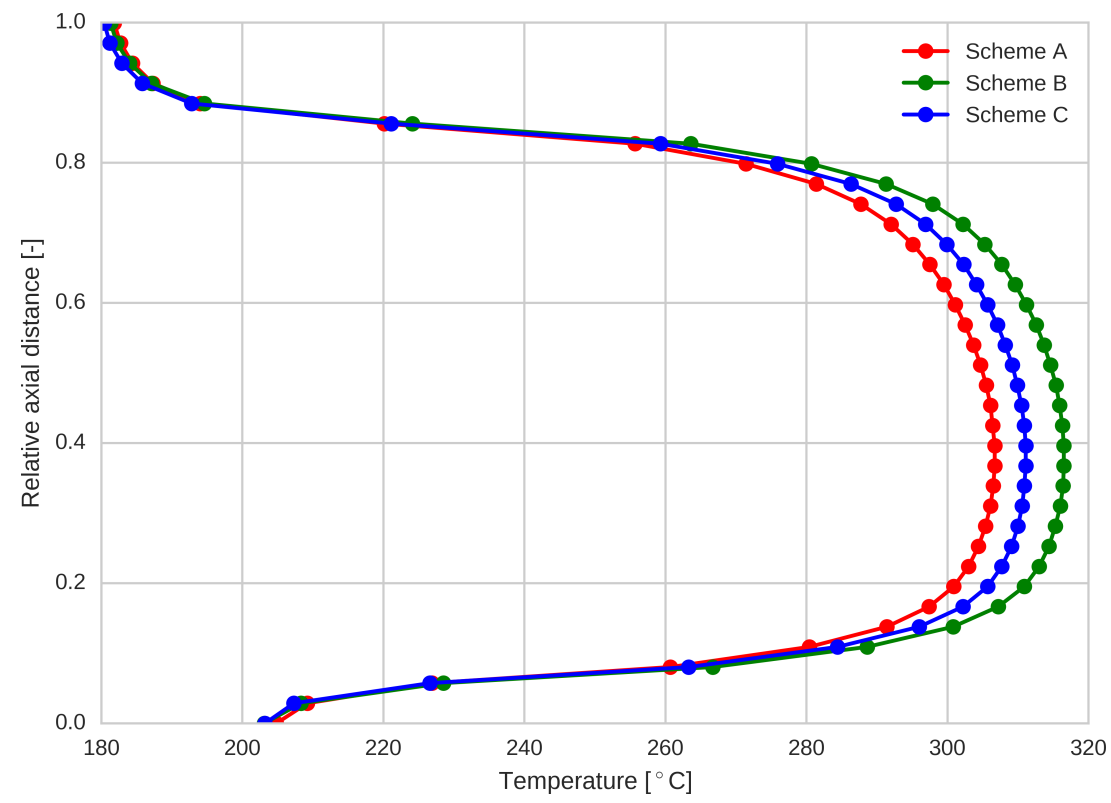

Figure 7. Axial dependence of cladding temperature of the most heated rod during different loads in the SKODA $1000 / 19$ storage cask.

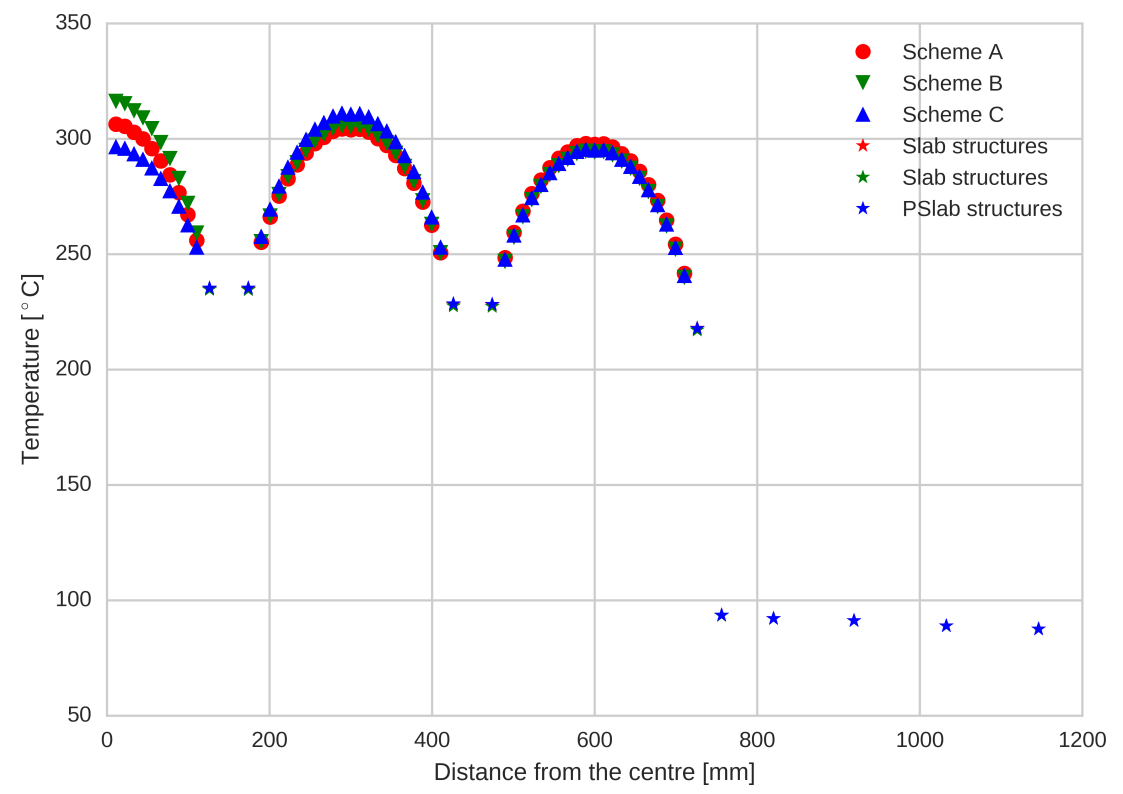

Figure 8. Radial dependence of temperature in the SKODA 1000/19 storage cask.

for the maximum cladding temperature of $350{ }^{\circ} \mathrm{C}$ is fulfilled and the axial distribution of maximal temperature of the most heated rod is presented in the Fig. 7 for three different load schema. In the Fig. 8 the temperatures are at the level where the maximum occurs plotted in radial direction. The last displayed data are plotted in the Fig. 9, where the dependence of heat power on time is shown. It can be clearly seen that even after 50 years the maximal temperatures are still high. As a result of this it is not necessary only to ensure temperature limits but also to preserve fuel integrity.

Finally the flow rates of all assemblies has been compared and summarized into Table 2. The interesting thing happened in assembly 2 in schemes B and
$\mathrm{C}$, where the total flow direction has switched from upwards to downwards. It was probably caused by the fact that the peripheral assembly 18 could not transfer more fluid and therefore a part of the flow has moved to different assemblies.

The work in this paper confirms that the spent nuclear fuel from VVER reactors can be characterized using COBRA-SFS code in a way similar to the fuel from western types of reactors. The simplified model has been created however there is a lot of possibilities for future work including changes in the COBRA code or creation of a more detailed model of the storage cask. Including different loads together with heterogeneous radial power is a possibility as well. 


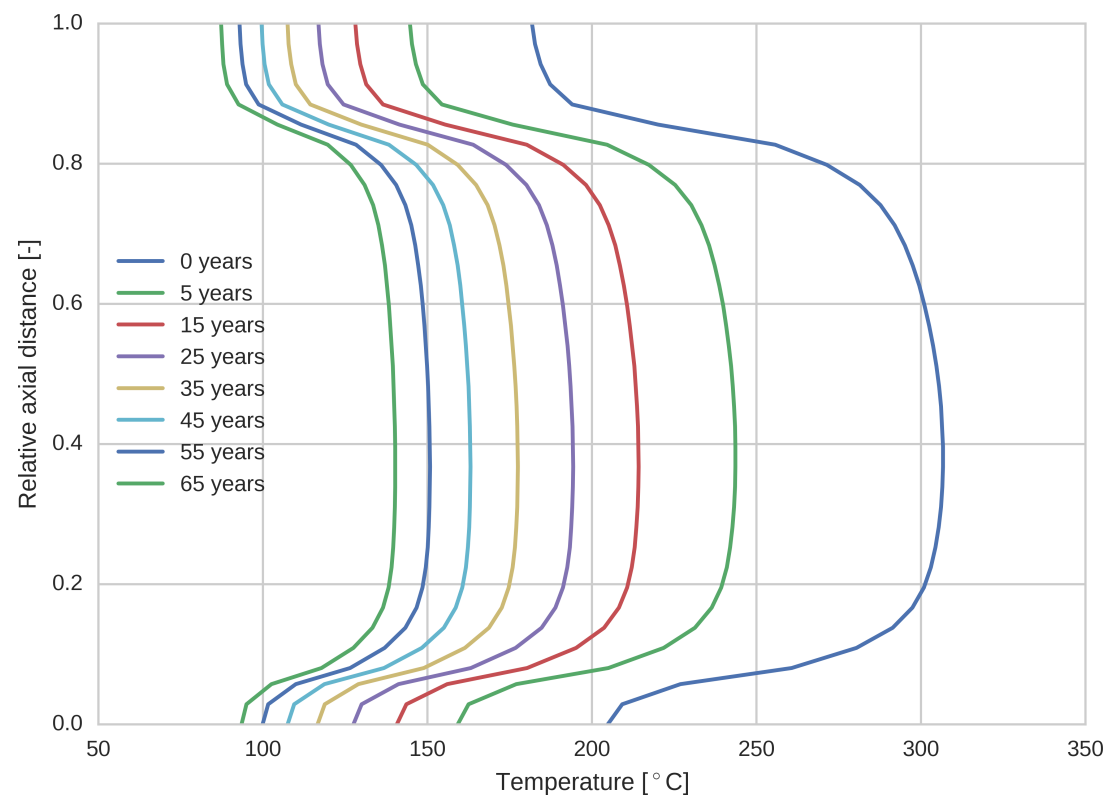

FigURE 9. Axial dependence of cladding temperature of the most heated rod on time during load scheme A in the SKODA 1000/19 storage cask.

\begin{tabular}{|c|c|}
\hline \multicolumn{2}{|l|}{ Fuel pellet: } \\
\hline Inner diameter $[\mathrm{mm}]$ & 1.2 \\
\hline Outer diameter [mm] & 7.6 \\
\hline Pellet height $[\mathrm{mm}]$ & $9-12$ \\
\hline Pellet density $\left[\mathrm{g} . \mathrm{cm}^{-3}\right]$ & $10.4-10.7$ \\
\hline Thermal conductivity $[\mathrm{W} / \mathrm{m} . \mathrm{K}]$ & 5 \\
\hline Heat capacity $[\mathrm{kJ} / \mathrm{kg} . \mathrm{K}]$ & 0.2470 \\
\hline$\alpha_{\text {gap }}\left[\mathrm{W} / \mathrm{m}^{2} . \mathrm{K}\right]$ & 16000 \\
\hline \multicolumn{2}{|l|}{ Fuel rod: } \\
\hline Inner cladding diameter $[\mathrm{mm}]$ & 7.73 \\
\hline Outer cladding diameter $[\mathrm{mm}]$ & 9.1 \\
\hline Rod length $[\mathrm{mm}]$ & 3925 \\
\hline Rod active length [mm] & 3680 \\
\hline Cladding material & Zr-4; E-110 \\
\hline \multicolumn{2}{|l|}{ Fuel assembly: } \\
\hline Average enrichment [\%] & $<5$ \\
\hline Burnable absorber & $\mathrm{Gd}_{2} \mathrm{O}_{3}$ \\
\hline Pitch $[\mathrm{mm}]$ & 12.75 \\
\hline Number of spacer grid & 8 \\
\hline Spacer grid material & E-110; steel \\
\hline Guide tube inner diameter $[\mathrm{mm}]$ & 10.9 \\
\hline Guide tube outer diameter [mm] & 12.6 \\
\hline Guide tube material & E-635 \\
\hline Fuel assembly width $[\mathrm{mm}]$ & 236 \\
\hline Assembly length $[\mathrm{mm}]$ & 4570 \\
\hline Linear power $\left[\mathrm{kW} \cdot \mathrm{m}^{-1}\right]$ & 16.0 \\
\hline Max. linear power $\left[\mathrm{kW} \cdot \mathrm{m}^{-1}\right]$ & 44.8 \\
\hline
\end{tabular}

TABLE 3. The main parameters of TVSA-T fuel [15].

\section{LIST OF SYMBOLS}

$\alpha$ Heat transfer coefficient $\left[\mathrm{W} \mathrm{m}^{-2} \mathrm{~K}^{-1}\right]$

$\eta \quad$ Dynamic viscosity $[\mathrm{Pas}]$

$\gamma$ Isobaric thermal expansion coefficient $\left[\mathrm{K}^{-1}\right]$

$\lambda$ thermal conductivity $\left[\mathrm{W} \mathrm{m}^{-1} \mathrm{~K}^{-1}\right.$ ]

$\rho$ Density $\left[\mathrm{kg} \mathrm{m}^{-3}\right]$

$c_{p}$ Isobaric heat capacity $\left[\mathrm{J} \mathrm{kg}^{-1} \mathrm{~K}-1\right]$

$g$ Gravitational acceleration $\left[\mathrm{m} \mathrm{s}^{-2}\right]$

$l \quad$ Characteristic length $[\mathrm{m}]$

$q$ Heat flux $\left[\mathrm{W} \mathrm{m}^{-2}\right]$

$C, c$ Coefficients [-]

$T$ Temperature $[\mathrm{K}]$

Gr Grashof's number [-]

$\mathrm{Nu}$ Nusselt's number [-]

$\operatorname{Pr}$ Prandtl's number [-]

Re Reynolds's number [-]

\section{ACKNOWLEDGEMEnTs}

The support from Student grant contest from Czech Technical University with code SGS16/252/OHK4/3T/14 is gratefully acknowledged. Many thanks belong to my supervisor Ing. Jiří Čížek and my consultants Ing. Martin Ševeček and Ing. Dušan Kobylka, Ph.D who provided insight and expertise that greatly assisted the research. I would also like to thank Ing. Lubomír Bureš for his constructive criticism and friendly advice during the project work.

\section{REFERENCES}

[1] Spent nuclear fuel storage in standalone nuclear systems. Safety guide BN-02.2. SUJB, Praha, 1st edn., 2010.

[2] C. WHEELER, R. MCCANN, N. LOMBARDO, et al. Hydra and cobra-sfs temperature calculations for castor-ic, rea-2023, castor-v/21, and tn-24p cask. Third 
International Spent Fuel Storage Technology Symposium: Workshop 1(1):77-98, 1986.

[3] D. RECTOR, J. CUTA, N. LOMBARDO. COBRA-SFS thermal-hydraulic analysis of the CASTOR-1C and REA 2023 BWR storage casks containing consolidated spent fuel. Pacific Northwest Laboratory, Richland, Washington, 1st edn., 1986.

[4] M. MCKINNON, J. CREER, T. MICHENER, et al. The TN-24P PWR spent fuel storage cask: testing and analysis. Electric Power Research Institute, Palo Alto, California, 1st edn., 1987.

[5] T. E. MICHENER, J. M. CUTA, D. R. RECTOR, et al. COBRA-SFS: Thermal-Hydraulic Analysis Code for Spent Fuel Storage And Transportation Casks. Battelle: Pacific Northwest National Laboratory, Richland, Washington 99352, 3rd edn., 1995.

[6] T. E. MICHENER, J. M. CUTA, D. R. RECTOR, H. E. ADKINS. COBRA-SFS: Thermal-Hydraulic Analysis Code for Spent Fuel Storage And Transportation Casks. Battelle, Pacific Northwest National Laboratory, Richland, Washington 99352, 1st edn., 2015.

[7] D. VLCEK. Residual heat power removal from spent nuclear fuel during dry and wet storage. Master thesis. DNR FNSPE CTU, Prague, 2018.
[8] L. E. HERRANZ, J. PENALAVA, F. FERIA. Cfd analysis of a cask for spent fuel dry storage. Annals of Nuclear Energy 2015(76):54-62, 2015. DOI:10.1016/j.anucene.2014.09.032

[9] T. FUNKE, P. BRICH. CASTOR 1000/19: Transport and storage cask for spent nuclear fuel from NPP Temelin. GNS, CEZ, 1st edn., 2008.

[10] R. D. MCCARTY. Thermophysical Properties of Helium-4 from 2 to $1500 \mathrm{~K}$ with Pressures to 1000 Atmospheres. National Bureau of Standards, Boulder, Colorado, 1st edn., 1972.

[11] MATWEB. available from 2018-05-07. Automation Creations, 1990.

[12] M. SEVECEK. Spent nuclear fuel behavior simulation during dry long-term storage in the storage and transportation casks CASTOR. Master thesis. DNR FNSPE CTU, Prague, 2014.

[13] R. L. COX. Radiative heat transfer in arrays of parallel cylinders. Tennessee Univ., Knoxville, 1976.

[14] H. WANG, J. K. MCCOY, D. STAHL. Spent nuclear fuel effective thermal conductivity report. U.S. Department of Energy, Las Vegas, 1st edn., 1996.

[15] L. SKLENKA. Provozní reaktorová fyzika. Vydavatelství ČVUT, Praha, 1st edn., 2001. 